\title{
細菌に依る糖分解に關する觀察（第九報） 高溫菌の糖分解について
}

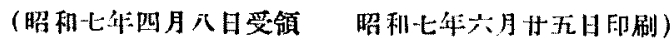

四方敬一赤很文是

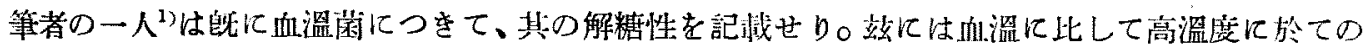
み發育する高溫菌隹つさて行へる處を冁ぜんとす。

高溫菌の分路はリービッヒ肉エキスより、福田 ${ }^{2}$ に從つて行ひ、其分類又同氏に依れり。

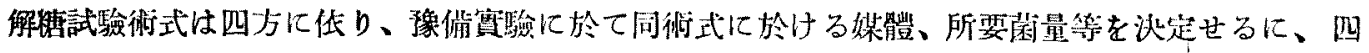

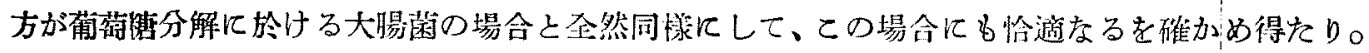

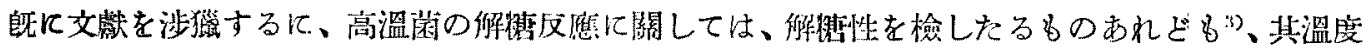

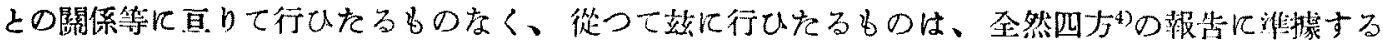
ことせ⿰口。

\section{糖分解と溫度との關係}

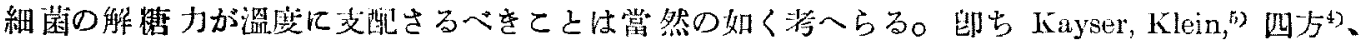

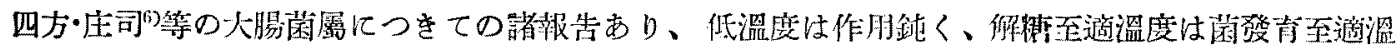
度より高をを示せり。

\section{第 1 節 高溫菌發肓と唔養溫度につきて}

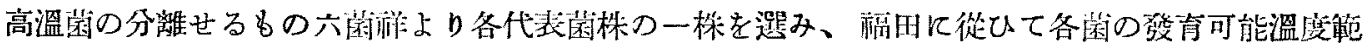
圍站に至適溫度を決定せり。但し使用培善基は $\mathrm{pH} 6.6$ のプイョンルして、寒天゙斜面培盖より約

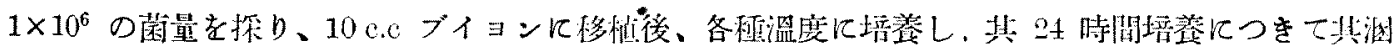
濁度、沈渣、菌膜形成等の度を觀祭して發肖程度を判定す。

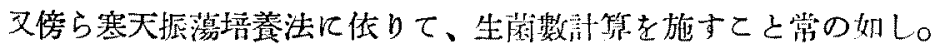

其成績第 1 表の吙し。

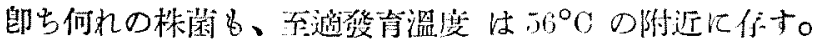

\section{第 2 節 高溫菌の解糖作用溫度について}

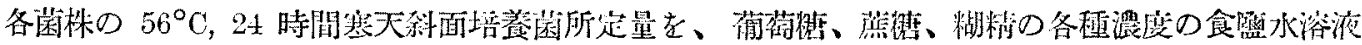

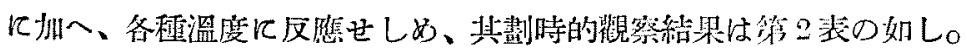

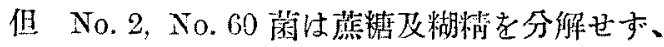

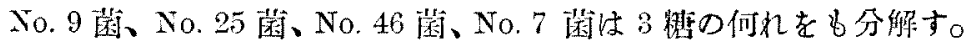

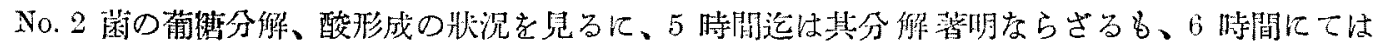

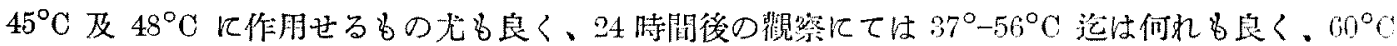

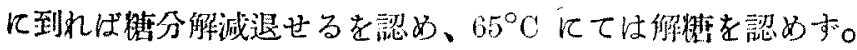

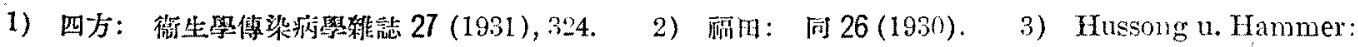
J. Bact., 25 (1928), 170; 其他㼛田交営. 4) 本誌, 52 (1931), 529. 5) Klein: O. Bakt., Orig. I, 63 (1912),

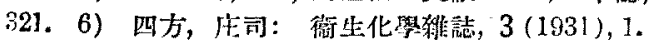




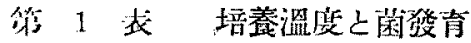

\begin{tabular}{|c|c|c|c|c|c|c|c|c|c|c|c|c|}
\hline 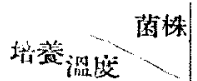 & \multicolumn{2}{|c|}{ 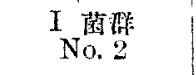 } & \multicolumn{2}{|c|}{ II 菌群 } & \multicolumn{2}{|c|}{$\begin{array}{l}\text { III 菌垹 } \\
\text { No. } 25\end{array}$} & \multicolumn{2}{|c|}{$\begin{array}{l}\text { IV 菌群 } \\
\text { No. } 46\end{array}$} & \multicolumn{2}{|c|}{$\begin{array}{l}\mathrm{V} \text { 菌磷 } \\
\text { No.7 }\end{array}$} & \multicolumn{2}{|c|}{$\begin{array}{l}\text { VI 菌群 } \\
\text { No. } 60\end{array}$} \\
\hline $37^{\circ} \mathrm{C}$ & - & $1 \times 10^{6}$ & - & $5 \times 10^{6}$ & - & $1 \times 10^{6}$ & - & $2 \times 10^{6}$ & - & $3 \times 14^{6}$ & - & $5 \times 10^{6}$ \\
\hline 40 & + & 14 & + & 47 & + & 17 & \pm & 15 & + & 12 & \pm & 10 \\
\hline $4: 2$ & $+t$ & 15 & + & 26 & ++ & 72 & + & 72 & ++ & 75 & + & 10 \\
\hline 45 & ++ & 55 & $+t$ & 54 & ++ & 70 & + & 80 & ++ & 68 & + & 37 \\
\hline 48 & + & 95 & + & 86 & + & 120 & + & 70 & ++ & 74 & $H$ & 35 \\
\hline 50 & $+t$ & 82 & $+1+$ & 110 & ++ & 161 & + & 65 & + & 95 & ++ & 130 \\
\hline 53 & ++ & 166 & $++t$ & 148 & ++ & 145 & ++ & 150 & +++ & 181 & ++ & 110 \\
\hline 56 & ++ & 121 & $+t$ & 146 & +++ & 180 & $H$ & 155 & +++ & 172 & +++ & 190 \\
\hline 60 & ++1 & 131 & +++ & 117 & ++ & 165 & $++t$ & 125 & $++t$ & 183 & +++ & 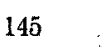 \\
\hline 65 & + & $5:$ & ++ & 102 & + & 90 & ++ & 59 & + & 81 & +++ & 105 \\
\hline 70 & \pm & 58 & - & 7 & ++ & 85 & \pm & $\bar{\tau}$ & \pm & 45 & + & 5 \\
\hline
\end{tabular}

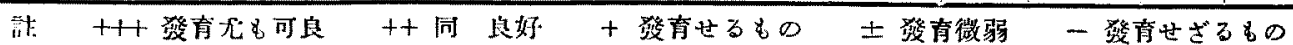

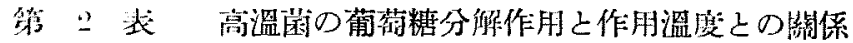

[A] No. 2 菌、 $50 \times 10^{8}$

\begin{tabular}{|c|c|c|c|c|c|c|c|c|c|c|c|c|c|c|}
\hline 作用洔閌 & 1 時閣 & 2 時問 & 3 洔間 & & & 時閣 & & & & & 24 時 & 持間 & & \\
\hline 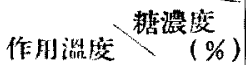 & 1.00 .5 & 1.00 .5 & $\begin{array}{lll}1.0 & 0.5 & 0.25\end{array}$ & 1.0 & 0.5 & 0.250 & 0.1 & 0.05 & 1.0 & 0.5 & 0.4 & 0.1 & 0.050 & 0.01 \\
\hline $37^{\circ} \mathrm{C}$ & +- & +- & $+t \pm \pm$ & ++ & \pm & \pm & - & - & ++ & $+H$ & $+1+$ & $+H$ & ++++ & - \\
\hline 40 & -- & -- & + \pm- & + & \pm & - & - & - & ++ & ++1 & $+1+$ & $++t$ & $++t$ & -- \\
\hline 42 & - & \pm \pm & + \pm \pm & $H$ & + & \pm & - & - & $t++$ & ++ & $+i+$ & ++1 & +++ & - \\
\hline 45 & -- & \pm \pm & + \pm \pm & ++ & +1 & ++ & + & + & ++ & +++ & +++ & $++t$ & +++ & - \\
\hline 48 & -- & - & \pm \pm- & ++ & + & + & - & - & +++ & ++ & +++ & $+1+$ & +++ & \pm \\
\hline 50 & - & - & \pm \pm- & ++ & \pm & - & - & - & ++ & + & + & + & $+\quad+$ & - \\
\hline 53 & -- & -- & \pm-- & ++ & \pm & - & - & - & ++ & ++ & +++ & $+++t$ & +++4 & - \\
\hline 56 & $-\quad-$ & - & \pm \pm \pm & + & \pm & \pm & - & - & ++ & +++ & $+1+$ & $t+t$ & $+++t$ & - \\
\hline 60 & -- & -- & $-\quad-$ & - & - & - & - & - & $+1+$ & ++ & ++1 & $+\quad-$ & - & - \\
\hline 65 & -- &.-- & --- & - & - & - & - & - & - & - & - & - & - & - \\
\hline
\end{tabular}

[B] No. 9 菌、 $51 \times 10^{5}$

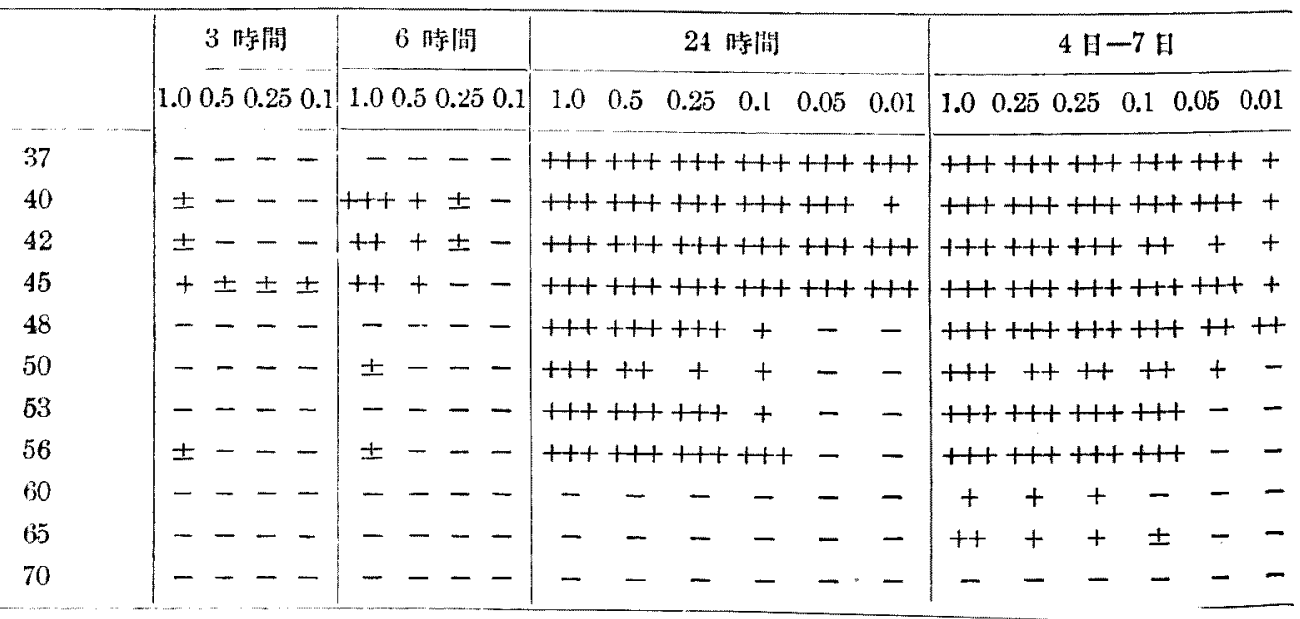


[C]: No. 25 藏, $58 \times 10^{8}$

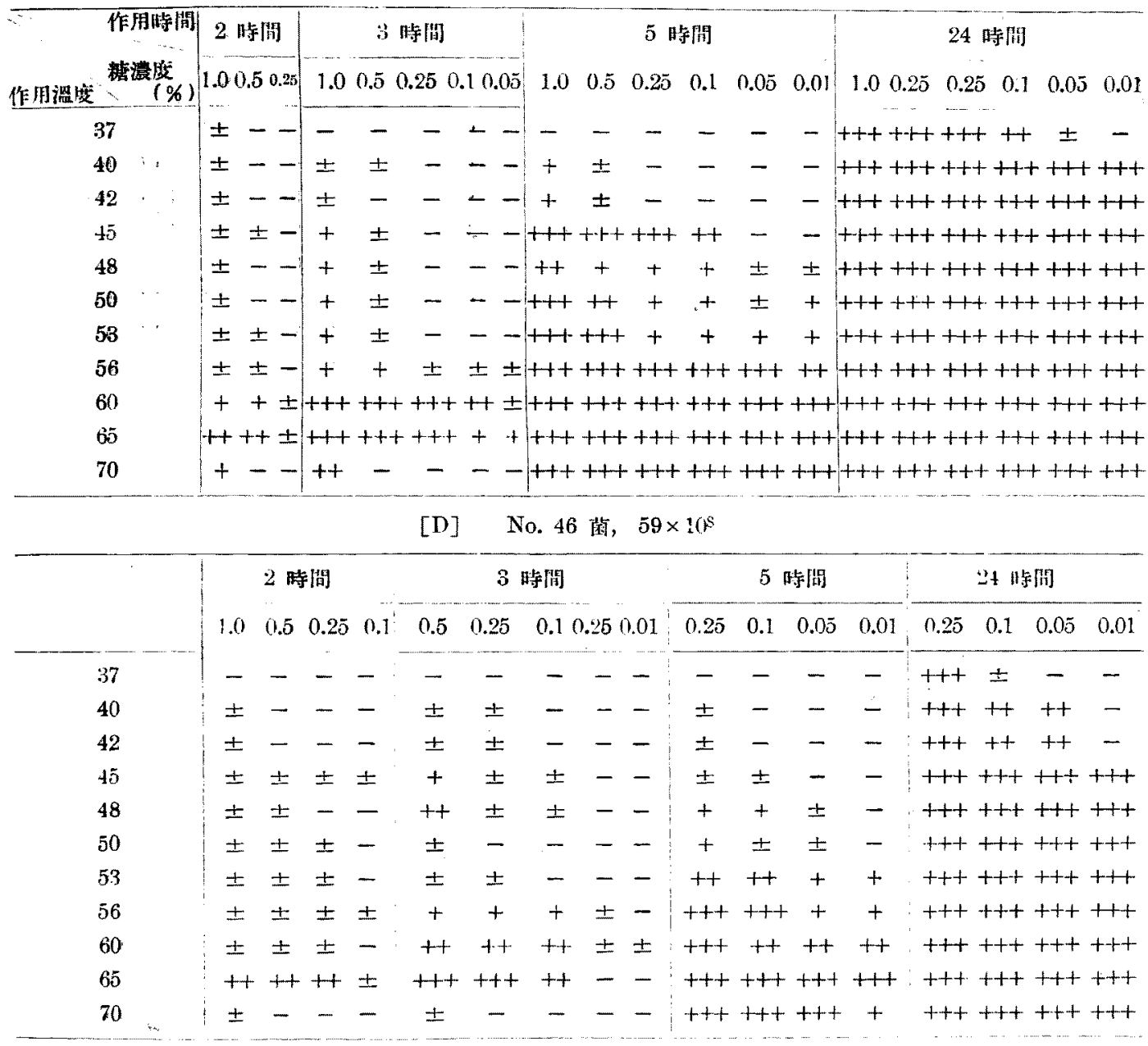

[E] No. 7 菌, $40 \times 10^{8}$

\begin{tabular}{|c|c|c|c|c|c|c|c|c|c|c|c|}
\hline & \multicolumn{5}{|c|}{6 時䦔 } & \multicolumn{6}{|c|}{24 時非 } \\
\hline & 1.0 & 0.5 & 0.25 & 0.1 & 0.05 & 1.0 & 0.5 & 0.25 & 0.1 & $0.0 \bar{j}$ & 0.01 \\
\hline 37 & \pm & \pm & \pm & \pm & - & + & ++ & ++ & ++ & + & ++ \\
\hline 40 & - & - & - & - & - & +++ & +++ & +++ & + & + & - \\
\hline 42 & - & - & - & - & - & $+t+$ & $+1+$ & ++ & +++ & +++ & - \\
\hline 45 & - & - & - & - & - & $++t$ & +1 & $+t+$ & +++ & +++ & - \\
\hline 48 & \pm & - & - & - & - & $++t$ & +++ & +++ & +++ & - & - \\
\hline 50 & - & - & - & - & - & $+t$ & $+1+$ & ++ & + & - & - \\
\hline 53 & - & - & - & - & - & $+t+$ & +++ & $+1+$ & $++t$ & - & - \\
\hline 56 & - & - & - & - & - & $+t+$ & + & ++ & + & - & - \\
\hline 60 & - & - & - & - & - & ++ & ++ & - & - & - & - \\
\hline 65 & - & - & - & - & - & $++t$ & $+t+$ & - & - & - & - \\
\hline 70 & - & - & - & - & - & - & - & - & - & - & - \\
\hline
\end{tabular}


[F] No. 60 菌, $36 \times 10^{8}$

\begin{tabular}{|c|c|c|c|c|c|c|c|c|c|c|c|c|c|c|c|c|c|}
\hline \multirow[b]{2}{*}{ 作用㳑委 } & \multicolumn{2}{|l|}{ 作用時間 } & \multicolumn{3}{|c|}{3 時間 } & \multicolumn{6}{|c|}{6 時䦎 } & \multicolumn{6}{|c|}{24 時閪 } \\
\hline & 糖篦度 & 1. & 0.5 & 0.25 & 1.0 & 1.0 & 0.5 & 0.230 & .10 & 0.05 & 0.01 & 1.0 & 00 & 0.25 & 0.1 & 0.05 & 0.01 \\
\hline & 37 & - & - & - & - & - & - & - & - & - & - & ++ & ++ & +++ & $+1+$ & ++ & - \\
\hline & 40 & - & - & - & - & + & \pm & \pm & - & - & - & $t+t$ & +++ & $+t+$ & ++ & $++t$ & - \\
\hline & 42 & - & - & - & - & \pm & - & - & - & - & - & $+t+$ & ++ & $++t$ & +++ & ++ & - \\
\hline & 45 & \pm & - & - & - & \pm & \pm & \pm & \pm & \pm & - & $+1+$ & $+1+$ & ++ & $+t+$ & +1 & - \\
\hline & 48 & \pm & - & - & - & $+t$ & $+t$ & + & + & - & - & +1 & $+t$ & +1 & ++ & $+t$ & \pm \\
\hline & 50 & \pm & - & - & - & \pm & \pm & \pm & - & - & - & ++ & ++ & ++ & $+t+$ & $+4+$ & - \\
\hline & 53 & \pm & - & - & - & \pm & \pm & \pm & - & - & - & +1 & ++ & ++ & $+1+$ & $H+$ & - \\
\hline & 56 & + & + & \pm & \pm & ++ & +++ & ++ & $+t$ & $+t$ & - & $+t+$ & $+t$ & $+t$ & $t+t$ & +1 & - \\
\hline & 60 & - & - & - & - & - & - & - & - & - & - & ++ & - & - & - & $L$ & - \\
\hline & 65 & - & - & - & - & - & - & - & - & - & - & +++ & - & - & - & - & - \\
\hline & 70 & - & - & - & - & - & - & - & - & - & - & - & - & - & - & - & - \\
\hline
\end{tabular}

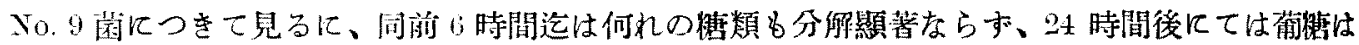

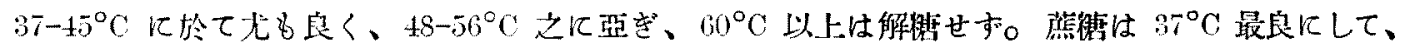

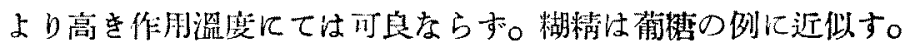

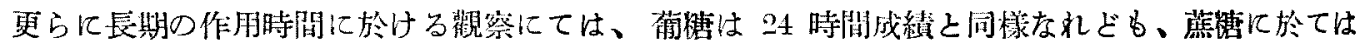

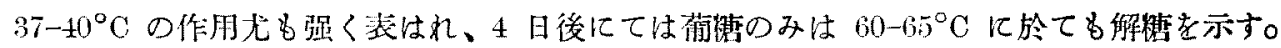

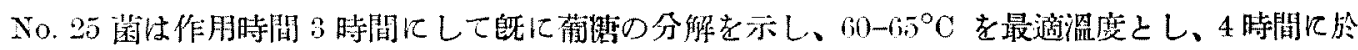
て此關係明かなり。蕉柫及糊粘の場合亦同じ。

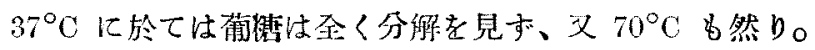

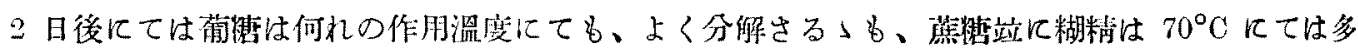
少不良应口。

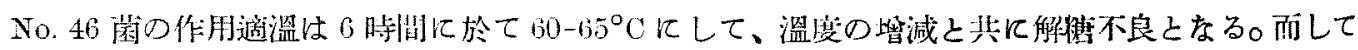

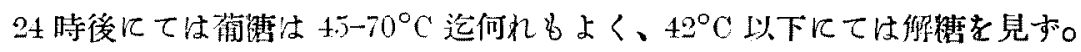

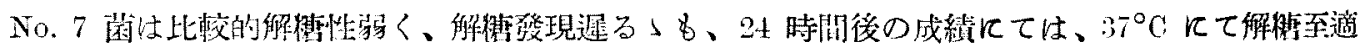
温度を倠す。

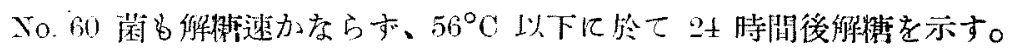

\section{第 3 節 唔養溫度と菌解糖カとについて}

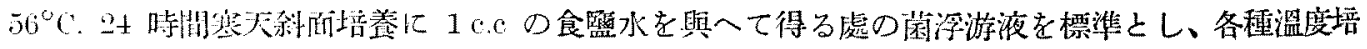

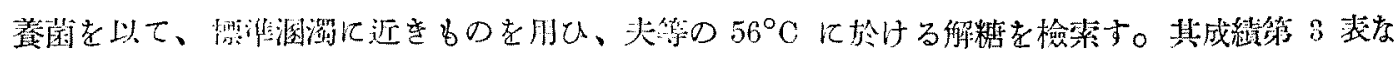
bo

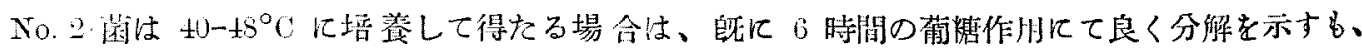

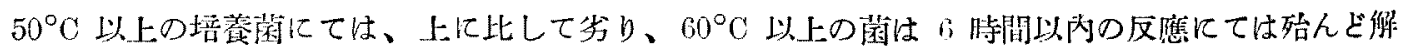

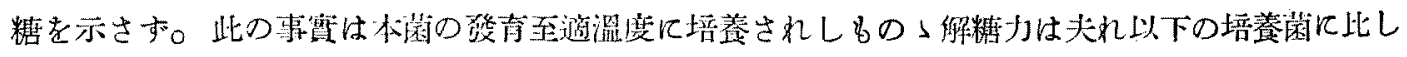
て低を能力なる事を示す。

No. 9 䒩は. No.2蒠と同じ。

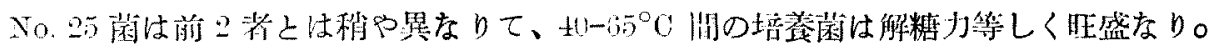


第 3 表 蒇苟糖分解、 $50^{\circ} \mathrm{C}$ 反應

[A] No. $2,50 \times 10^{8}$

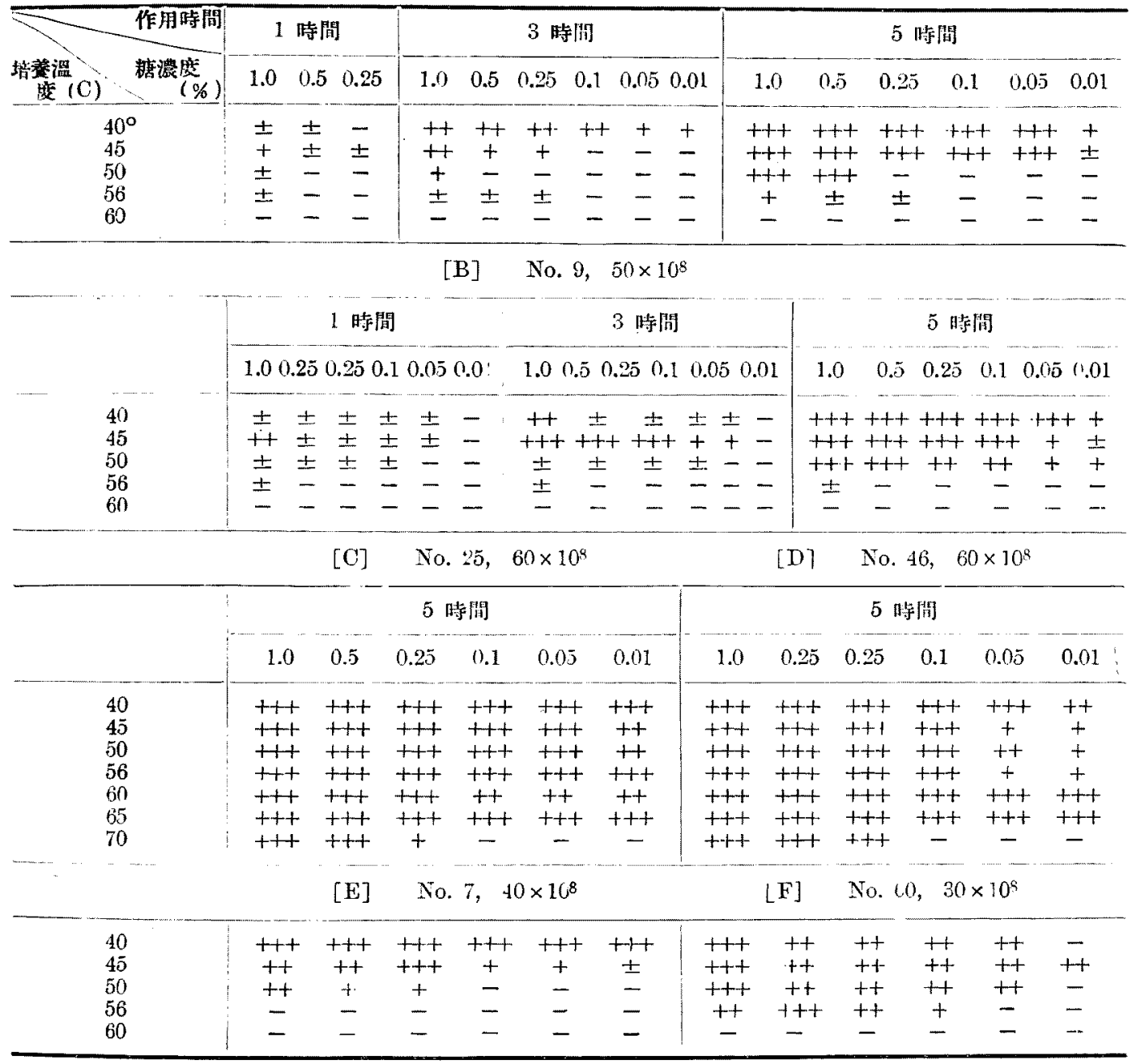

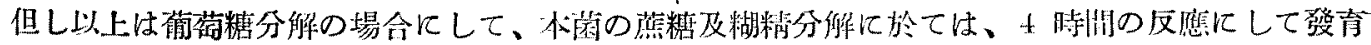

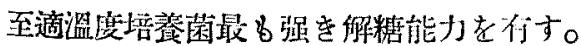

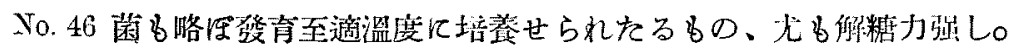

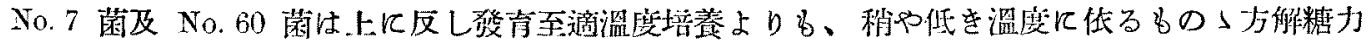
强 $\mathrm{O}_{\mathrm{O}}$

\section{第 4 節 菌解糖至適溫度と菌發育至適溫度について}

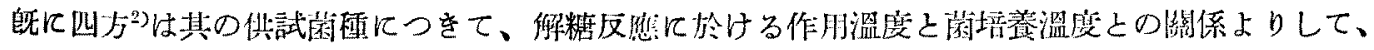

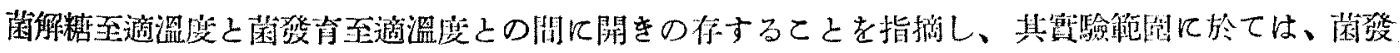

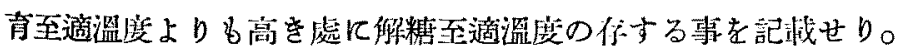

高溫菌に關しては、等者等の實驗結果を綜合するに、 


\begin{tabular}{|c|c|c|c|c|}
\hline 蒔 & 楎 & 㕠有經過淰洨 & 柳糖經滑溫度 & 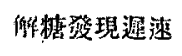 \\
\hline \multicolumn{5}{|c|}{ 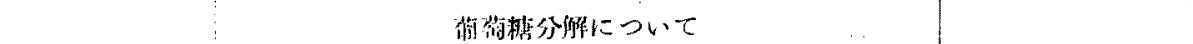 } \\
\hline No & 2 & $53-60^{\circ}$ & $45-48^{\circ}$ & 稍䞷 \\
\hline No & $y$ & $50-60^{\circ}$ & $37-45^{\circ}$ & 稍逭 \\
\hline No & 35 & $50-60^{\circ}$ & $60-65^{\circ}$ & 速， \\
\hline No & 46 & $53-60^{\circ}$ & $60-65^{\circ}$ & 稍速 \\
\hline No & 7 & $53-60^{\circ}$ & $37^{\circ}$ & 㡝 \\
\hline No & 60 & $50 \quad 65^{\circ}$ & $56^{\circ}$ 以下 & 荤 \\
\hline
\end{tabular}

即ち供彺せる高溫菌代表株 6 株につをて見るに、菌發有至適溫度と解糖至適溫度とは何れの場合 にb一致せす、、多くは後者は前条に比して低溫に倞し、此關係は全く四方のなせる血溫菌の場合と

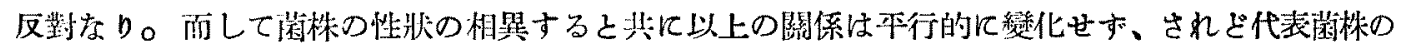

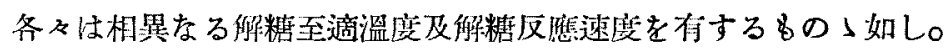

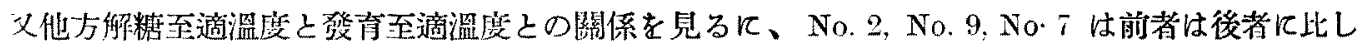
て著るしく低く、No. 60 は网溫度咯々一致し、他は稍や高し。斯くの如を相異は何に因するや份不

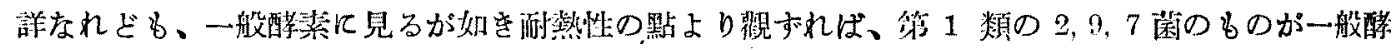
素と同一性肰を持つるの」如く見らる。

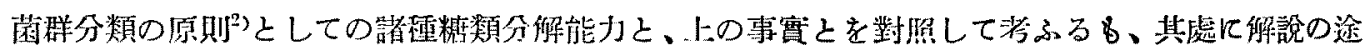

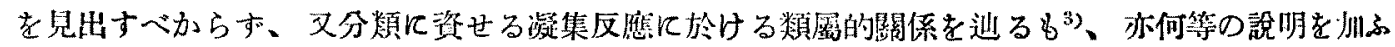

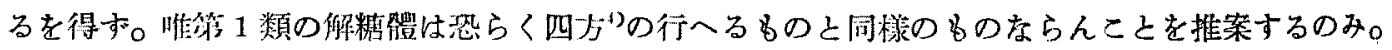

\section{結論}

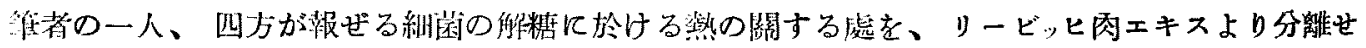

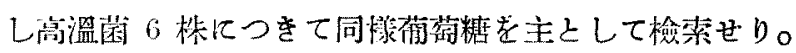

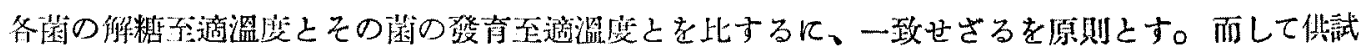

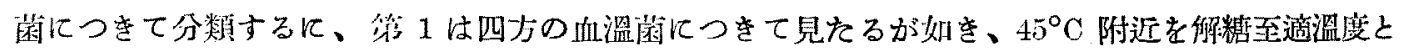

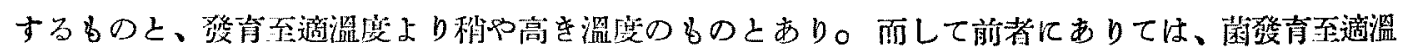

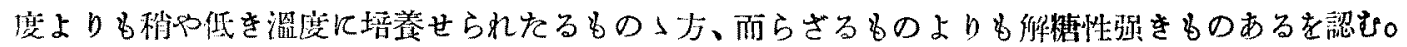
此閣係は四力の行ひたる大腸菌虺の場合之類似す。

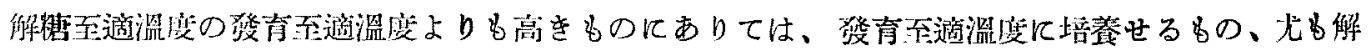
楉性强し。

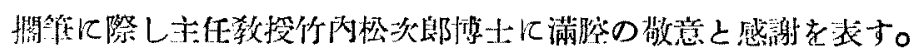

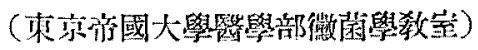

1)，4）赫須：来發表 